\title{
NOTICIÁRIO
}

\section{REPAROS À ZOOLOGIA DOS DICIONÁRIOS. III. AVES}

\author{
Messias Carrera $^{1}$
}

\begin{abstract}
"Os dicionários são como os relógios; o pior é melhor do que nenhum, e nem do melhor se pode esperar que seja totalmente exato."

Samuel Jonhson - em Paulo Ronai, Dicionário de Citações.
\end{abstract}

Representam estes "Reparos" modesta contribuição ao aprimoramento da informação zoológica que, divulgada nos dicionários, na verdade, sempre se quer cientificamente correta.

Os vocábulos relacionados à Ornitologia que de imediato chamaram nossa atenção, parecendo merecer comentário corretivo, foram colhidos em dois grandes dicionários da língua portuguesa: o Novíssimo de Laudelino Freire (DLF), $3^{\mathrm{a}}$ edição (1957), e o Brasileiro Melhoramentos (GDM), $8^{\mathrm{a}}$ edição (1975). "Reparos" sobre insetos foram publicados na Revista Brasileira de Entomologia (volume 35 (2): 469-474) e, sobre moluscos, no Boletim Informativo da Sociedade Brasileira de Malacologia (número 105: 11-14).

As correções, ora divulgadas nesta nota, estão muitíssimo longe de exprimirem uma revisão completa e, de modo nenhum, significam desapreço aos léxicos citados.

AIRO - Diz o GDM que este vocábulo designa "...uma ave marinha da família dos alcedinídeos (Uria aalge) que vive no litoral do Alaska."

A indicação de família para esta ave representa uma inexatidão, pois o gênero Uria, citado na definição, contendo espécies exclusivamente boreais, entre elas o airo, pertence à família Alcidae (Ordem Charadriiformes) e não à Alcedinidae (Ordem Coraciiformes), como erradamente foi assinalado pelo dicionário. O gênero tipo de Alcidae é Alca, o de Alcedinidae é Alcedo; na família Alcedinidae encontram-se as aves popularmente chamadas de "martim-pescador", em sua maioria habitantes das regiões tropicais do Velho Mundo.

ALCEDINÍDEOS - Família de aves definida no GDM como "vasta", o que me parece exagero, pois o número de espécies que a compõe é pouco mais de 80 , ao contrário de outras formadas por número muito maior de espécies.

O DLF registra alcedonídeos em vez de Alcedinídeos e informa que é uma "...família de aves que tem como tipo o maçarico." Ora, esta ave pertence à

1) Rua Catanumi 144, Interlagos, 04788-010 São Paulo, São Paulo, Brasil. 
Ordem Charadrïformes e, portanto, não pode ser Alcedinídeo, família da Ordem Coraciiformes.

AMBULADORES - "Grupo de pássaros corvinos, conirrostros, chamados também corviformes." Esta definição se encontra em ambos os dicionários compulsados; além de errônea, pouco esclarece o consulente, que continua sem saber o que são aves ambuladoras. Trata-se de uma antiga denominação dada a um grupo de pássaros que, frequentemente, caminha pelo chão, colocando um pé depois o outro, em oposição a aquele que anda saltitando. Em várias categorias taxonômicas encontram-se pássaros ambuladores, principalmente entre as espécies do gênero Corvus, às quais, em Portugal, dão o nome de corvo. $\mathrm{Na}$ realidade estes pássaros não são conirrostros, nem corvinos, nem corviformes, mas Corvídeos da Ordem Passeriformes. No Brasil os Corvídeos estão representados por nove espécies, todas do gênero Cyanocorax, vulgarmente chamadas de gralha.

ANTÃ - Definem os léxicos examinados: "Pequeno periquito do Maranhão (Poranduba maranhense)." Assim elaborada, esta definição induz o consulente a admitir que Poranduba maranhense é o nome científico do tal periquito do Maranhão. Nada disso. Poranduba maranhense é o nome de um livro escrito por Frei Francisco Nossa Senhora dos Prazeres (no século Francisco Fernandes Pereira), no qual foi assinalado o nome vulgar de antã para o minúsculo Psitacídeo ( $c f$. Revista Trimestral do Instituto Histórico e Geográfico Brasileiro, 1891, Tomo 54, p.178). Segundo informação verbal de Hélio Ferraz de Almeida Camargo, ornitólogo do Museu de Zoologia da USP, Forpus crassirostris flavissimus, que vive no Maranhão e em Pernambuco, talvez seja o periquito antã.

ASTUR - O GDM registra este vocábulo, definindo-o como um gênero dos açores considerado "...em algumas classificações subgênero do gênero Accipiter."

Antigamente os açores e formas afins eram incluidas em dois gêneros: Astur e Accipiter. Há muitos anos, porém, estes Falconiformes estão reunidos somente em Accipiter (Astur é sinônimo), abrangendo algumas dezenas de espécies distribuidas por várias regiões do mundo; no Brasil estas aves de rapina são vulgarmente chamadas de gavião-papa-pinto e tauató-pintado.

GIMNORRINO -Segundo o GDM este vocábulo se refere a um "gênero (Gymnorhina) de aves passariformes, australianas, do tamanho de um pequeno corvo, comumente incluido na família dos lamnídeos."

Esta definição, comparando aves australianas a um pequeno corvo, suscita dúvida. Que corvo? Certamente a algum Corvídeo europeu e não ao corvo que, no Brasil, chamam de urubu.

Há outra questão interessante a assinalar. A nomenclatura ornitológica mantém em seu elenco de gêneros dois de grafia muito parecida, Gymnorhina e Gymnorhinus, pertencentes a famílias diferentes. Gymnorhina é um gênero da família Cracticidae; Gymnorhinus da família Corvidae. As espécies de Gymnorhina ocorrem na Austrália e são pouco aparentadas aos Corvidae; 
Gymnorhinus contem apenas uma espécie da América do Norte, Gymnorhinus cyanocephala, vulgarmente chamada, no México, de "Piñon Jay".

Verifica-se, assim, constituir grave erro do dicionário assinalar que Gymnorhina comumente se coloca na família dos Lamniídeos, mesmo porque esta família envolve espécies de peixes, não de aves, como afirma o próprio dicionário ao definir Lamniídeo. Provavelmente esta confusão se deva ao fato de existir a família Laniidae, onde se incluem aves com caracteres intermediários entre Cracticidae e Corvidae (cf. P.P. Grassé, 1950, Traité de Zoologie, Vol. XV, p.1011).

JURUTI - Para o DLF as jurutis são representantes da família dos peristerídeos, denominação esta há muitos anos fora de uso na nomenclatura das aves. Na América do Sul apenas uma família, a dos Columbídeos (Ordem Columbiformes) encerra todos os pombos, jurutis e rolas.

No GDM a juruti-verdadeira recebeu erradamente o nome científico e a caracterização próprios da juruti-vermelha. O certo seria: J.-verdadeira: (Leptotila rufaxilla), ave de colorido bruno-avermelhado no dorso e branco no ventre; penas da cauda com mancha branca arredondada. J.-vermelha: duas espécies desta juruti ocorrem no Brasil, Geotrygon montana e Geotrygon violacea; em ambas, no macho, o dorso é ruivo-purpurino, em extensão variável; na fêmea, essa região do corpo é pardacento-oliva. Nas jurutis-vermelhas inexiste a mancha branca arredondada nas penas da cauda (informação verbal de Hélio Ferraz de Almeida Camargo).

LOFORNIS - O GDM define: "Gênero (Lophornis) de aves coraciformes da família dos Troquilídeos, que inclui várias espécies sul-americanas de beija-flores..." Esta definição está errada, pois os Troquilídeos não são aves Coraciiformes; os beija-flores pertencem à Ordem Trochiliformes.

PICA-PAU - O GDM registra: "...Pica-pau-de-cabeça-amarela (Phloecestes robustus)..." Errado; este nome científico era dado antigamente ao pica-pau-de-cabeça-vermelha, cuja figura o dicionário estampa. Atualmente este pica-pau, cientificamente, se denomina Campephilus robustus. O nome que a Ciência deu ao pica-pau-de-cabeça-amarela é Celeus flavescens.

PSÍTACO - O GDM define este vocábulo do seguinte modo: "Gênero Psittacus de aves da família dos psitacídeos, representado no Brasil pelo periquito-verde (Psittacus pullarius ou rufirostris)".

$\mathrm{Na}$ verdade, o mais certo seria dizer que o gênero Psittacus, criado por Lineu, compreendia no passado várias espécies do Brasil; hoje, porém, dá-se ao Psittacus rufirostris denominação diferente, Brotogeris versicolurus tirica; é um pequeno periquito que ocorre em grande parte do território brasileiro. Psittacus pullarius é da fauna africana, mudou de gênero e chama-se agora Agapornis pullaria.

PSITÁCULA, PSITÁCULO - O GDM remete o consulente destes vocábulos para Psítaco, estabelecendo assim uma impropriedade. Psittacula é um gênero distinto de Psittacus e a nomenclatura zoológica reconhece sua validade para uma quinzena de espécies da Ásia e da África. As espécies brasileiras, antes 
incluidas em Psittacula, pertencem hoje ao gênero Forpus, onde se incluem os nossos menores Psitacídeos, como os tuins.

SABIAPOCA - Vocábulo registrado no GDM duas vezes. A primeira entrada não se refere ao sabiapoca, mas ao sabiapiri, também chamado sabiáda-praia (Mimus gilvus); a segunda entrada refere-se ao sabiapoca ou sabiá-decampo (Mimus saturninus frater) (cf. Olivério M. Oliveira Pinto, 1944, Catálogo de Aves do Brasil, $2^{\mathrm{a}}$ parte, p.353).

TINÓCORO - O GDM informa: "... tinócoros são aves galiformes da família dos tinocoritídeos." Não é bem assim. Thinocorus é um gênero da família Thinocoridae, pertecente à Ordem Charadrïformes; suas espécies não ocorrem no Brasil; são aves da região andina que voam a grandes altitudes ( $c f$. Schauensee, 1966, "Birds of South America", p.100-101).

TROGONÍDEO - A figura que o GDM estampa não é a de um Trogonídeo e muito menos a de um "quetzal", mas sim a do "calau", ave asiática da Ordem Coraciiformes, família Bucerotidae, cujo nome científico é Bucerus bicornis (vide neste mesmo dicionário, em "calau", figura idêntica dada ao "quetzal"). A ave que se denomina "quetzal" é um Trogonídeo da América Central que ostenta plumagem de grande beleza; ela figura no emblema da bandeira da Guatemala e em seus selos postais.

AGRADECIMENTO. Dr. Hélio Ferraz de Almeida Camargo, ornitólogo do Museu de Zoologia da Universidade de São Paulo, tornou-se credor de minha graditão, concedendo-me valioso auxilio na execução deste artigo. Sem o subsídio dos seus conhecimentos ornitológicos este trabalho estaria demasiadamente imperfeito.

Recebido em 15.X.1991; aceito em 25.Xl.1993. 